\title{
Produtividade e Desempenho Exportador das Firmas na Indústria de Transformação Brasileira
}

\author{
- Alvaro barrantes Hidalgo* - Daniel da Mata **
}

\begin{abstract}
RESUMO
$O$ processo de abertura comercial trouxe mudanças importantes para a economia brasileira. As empresas melhoraram a produtividade a fim de se inserirem de forma competitiva no mercado internacional. Este trabalho analisou as diferenças de produtividade entre firmas exportadoras e firmas não exportadoras no Brasil. Utilizando o teste não paramétrico de Kolmogorov-Smirnov, comparam-se as distribuições de produtividade com dados ao nível de firmas. Os resultados encontrados mostram claramente maiores níveis de produtividade para as firmas exportadoras do que para as firmas não exportadoras. Ademais, as evidências encontradas mostram-se mais robustas para o grupo de firmas de pequeno porte vis-à-vis as firmas de grande porte. Quanto à explicação dessas diferenças, os resultados encontrados parecem dar suporte à hipótese de seleção, ou seja, o maior nível de produtividade das firmas exportadoras aparenta ser fruto de processos de seleção das firmas não apenas na entrada, mas também na saída do mercado de exportação. Por outro lado, os resultados encontrados não confirmam a existência de processos de aprendizado no mercado exportador brasileiro. Durante o período considerado, as diferenças entre as taxas de crescimento da produtividade das firmas exportadoras e das não exportadoras não foram significantes.
\end{abstract}

Palavras-Chave

produtividade, firmas exportadoras, Brasil

\section{ABSTRACT}

The trade opening process made important adjustments in the Brazilian economy. Several firms enhanced their productivity in order to enter foreign market competitively. This paper analyzed the productivity differences between exporting and non-exporting firms in Brazil. Using the Kolmogorov-Smirnov nonparametric test, we compare productivity difference in firm-level data. The results reveal higher productivity levels in exporting firms compared to non-exporting ones. Besides, the findings are more robust to the group of smaller firms. Concerning the explanation of those differences, the results appear to support the hypothesis of selection, i.e., the reason for the higher productivity level of exporting firms seems due to selection processes not only accrued of entering foreign markets, but also of exiting them. On the other hand, the results do not confirm the existence of a learning process in the exporting market. During the period under analysis, the firms' productivity growth divergences were not significant.

KEYWORDS productivity, exporting firms, Brazil

\section{JEL CLASSIFICATION}

FI5, FI6

+ Os autores agradecem os comentários e sugestões de João De Negri, Bruno Araújo, Fernando Freitas, Patrick Alves e de dois pareceristas anônimos desta revista. Versão anterior deste trabalho foi apresentada no XXXVI Encontro Nacional de Economia da ANPEC, realizado em Salvador-BA, em dezembro de 2008. Os autores agradecem sugestões recebidas por Flávio Benevett Fligenspan, Lucas Pedreira do Couto Ferraz e Marta dos Reis Castilho durante tal encontro. Erros e omissões remanescentes são naturalmente de responsabilidade dos autores.

* Professor do Departamento de Economia da Universidade Federal de Pernambuco e Pesquisador do CNPq. Doutor em Economia - USP. Endereço para contato: Universidade Federal de Pernambuco. Departamento de Economia - Av. dos Economistas, s/n, Cidade Universitária. Recife - PE. CEP 50670-90I. E-mail: hidalgo@ufpe.br

** Economista do Instituto de Pesquisa Econômica Aplicada (IPEA). Endereço para contato: SBS Quadra 0I, Bloco J, Sala 308. Brasília - DF. CEP: 70076-900. E-mail: daniel.damata@ipea.gov.br.

(Recebido em julho de 2007. Aceito para publicação em março de 2009). 


\section{$1 \quad$ INTRODUÇÃO}

A partir do fim da década de 1980, os formuladores da política econômica introduziram algumas medidas de livre comércio, a fim de tornar a economia brasileira mais competitiva e moderna. O processo gradual de abertura foi iniciado em julho de 1988, levando a uma redução na tarifa média de 130\% vigente em 1987 para menos de $15 \%$ em 1994. Durante o período houve, da mesma forma, uma redução na dispersão tarifária. Tal processo foi intensificado no início da década de 90 e a abertura comercial passou também a significar a eliminação das barreiras não tarifárias. Esperava-se que todo esse conjunto de medidas de abertura comercial levasse a uma melhoria na eficiência da economia brasileira, ocasionando melhor alocação intersetorial dos recursos e criando as bases para uma inserção competitiva na economia internacional. Deste modo, a abertura da economia pretendia promover uma mudança em relação ao passado e integrar a economia brasileira na globalização, onde as atividades menos competitivas deveriam ser substituídas por outras de maior produtividade.

A abertura comercial de fato promoveu mudanças na produtividade brasileira, sendo importante ter um melhor conhecimento sobre a dimensão dessas mudanças. As análises sobre produtividade no Brasil, entretanto, são geralmente com foco em setores econômicos agregados (ver, por exemplo, BONELLI; FONSECA, 1998; ROSSI; FERREIRA, 1999; HIDALGO, 2002; SABÓIA, 2004 e FERREIRA; GUILLÉN, 2004). Os estudos sobre o crescimento da produtividade ao nível da firma, e sua relação com o desempenho exportador, são relativamente poucos. Entre eles, cabe destacar o trabalho de Gomes e Ellery (2007) que, a partir de dados da Pesquisa Industrial Anual (PIA) para o ano de 1999, em nível de firma, verificaram que as firmas exportadoras são maiores e mais produtivas, em termos de produtividade do trabalho, que as que atuam apenas no mercado interno. ${ }^{1}$ Segundo os autores, a produtividade média das firmas que exportam é aproximadamente $60 \%$ maior que a produtividade média das que não exportam. Gomes e Ellery (2007) encontraram também que firmas que exportam para muitos mercados são mais produtivas que firmas que exportam para poucos mercados. Hay, 2001 e Ferreira e Rossi (2003) trabalhando com dados setoriais, também encontraram evidências da relação entre produtividade e exportação no Brasil.

Do ponto de vista teórico as novas teorias sobre comércio identificam os determinantes do comércio ao nível da firma e em que a produtividade desempenha papel muito importante - ver, por exemplo, Melitz (2003); Delgado, Farinas e Ruano

1 Em nível internacional, este é um resultado já consolido. Ver a respeito Tybout (2003), que apresenta uma resenha das evidências empíricas internacionais. Ver também outras evidências internacionais recentes encontradas por Eaton et alii (2004) e Bernard et alii (2003). 
(2002); Dosi G. (1988); Roberts e Tybout (1997), e Bernard e Jensen (2004). Segundo esses modelos teóricos, a seleção e o aprendizado das firmas no comércio internacional podem aumentar a produtividade das mesmas com efeitos positivos sobre o aumento das exportações.

Dessa forma, o objetivo do presente trabalho consiste em estudar melhor a produtividade das firmas industriais brasileiras e mensurar as diferenças de produtividade entre firmas exportadoras e firmas não exportadoras. Pretende-se conhecer o papel da produtividade das firmas no crescimento e desempenho recente das exportaçóes brasileiras. $\mathrm{O}$ trabalho visa mostrar as diferenças de produtividade para as firmas exportadoras e não exportadoras dos setores da indústria da transformação para o período pós-abertura comercial (especificamente, entre 1997 e 2003). O estudo dessa questão é relevante não apenas para o entendimento dos níveis de produtividade ao nível das firmas, mas também para a formulação da política industrial e tecnológica do comércio exterior brasileiro.

O trabalho pretende averiguar, portanto, se firmas exportadoras possuem maior produtividade $v i s-\grave{a}$ - $v i s$ firmas que nunca exportaram. Em outras palavras, se existe ou não um processo de seleção de empresas que participam do mercado global. Ademais, estuda-se se há maior crescimento da produtividade de firmas que exportam do que as que não exportam. Isto é, se além de seleção existe um processo de aprendizado de empresas que vendem seus produtos no mercado internacional. Um exercício complementar é realizado a fim de examinar se o destino das exportações pode influenciar nos resultados sobre a potencial seleção e aprendizado de firmas no comércio internacional.

É válido frisar que dois conceitos de produtividade foram empregados: produtividade total dos fatores (PTF) e produtividade do trabalho (PL). No que concerne à parte metodológica do trabalho, as diferenças entre produtividades das firmas exportadoras e não exportadoras são abordadas comparando-se toda a distribuição da produtividade (teste não paramétrico de Kolmogorov-Smirnov). Maiores detalhes podem sem encontrados na seção referente aos dados e à metodologia empregada.

O trabalho pretende assim contribuir para o debate sobre o assunto, apresentando novas evidências sobre o impacto da presença no mercado internacional sobre a produtividade ao nível das firmas e sua relação com o desempenho exportador. Em relação aos trabalhos anteriormente realizados para o Brasil, esta pesquisa considera não apenas um período mais amplo, mas também analisa a produtividade total dos fatores, além da produtividade do trabalho, a fim de chegar a resultados mais robustos. Dessa forma, dispondo de um período de tempo mais longo procura-se também conhecer melhor a direção de causalidade da correlação no tempo entre crescimento 
de produtividade e participação no mercado exportador. Para alcançar esse objetivo, na seção 2 serão apresentados os aspectos teóricos e metodológicos utilizados. A terceira parte versa sobre os resultados obtidos da análise e, por último, na seção 4 serão apresentadas as conclusões do trabalho.

\section{ASPECTOS TEÓRICOS E METODOLOGLA}

\subsection{Aspectos Teóricos}

$\mathrm{Na}$ literatura econômica sobre produtividade, tem sido evidenciadas diferenças de produtividade ao nível das firmas. Trabalhos realizados internacionalmente têm verificado que essas diferenças persistem ao longo do tempo e estão relacionadas à entrada ou não das firmas no comércio internacional.

Diversos argumentos teóricos foram desenvolvidos na literatura a fim de explicar as diferenças de produtividade entre firmas exportadoras e não exportadoras. Em primeiro lugar, alega-se que as firmas que participam do comércio internacional estão mais expostas à competição. Sendo a competição nos mercados de exportação maior do que no mercado doméstico, ele oferece, portanto, menos oportunidades para as firmas ineficientes. O segundo argumento para explicar a produtividade maior das firmas exportadoras se apoia nos modelos de dinâmica industrial. Esses modelos defendem a existência de uma relação entre padrões de entrada e saída e diferenças de produtividade ao nível da firma. Argumenta-se que, os exportadores têm de arcar com maiores custos irrecuperáveis (do tipo sunk costs) do que as firmas orientadas para o mercado doméstico. Mesmo se considerarmos pressóes competitivas semelhantes no mercado externo e no mercado doméstico, diferenças nos custos irrecuperáveis de entrada podem explicar diferenças de produtividade entre firmas exportadoras e firmas orientadas para o mercado doméstico. A experiência mostra que em um país em desenvolvimento como o Brasil as firmas industriais precisam fazer investimentos prévios no mercado exterior a fim de dar a conhecer os produtos e ter sucesso nas exportaçóes.

Esses dois argumentos para explicar diferenças de produtividade compartilham a ideia de que os mercados de exportação selecionam as firmas mais eficientes dentre o conjunto de firmas potenciais entrantes no comércio internacional. O terceiro argumento para explicar a produtividade maior das firmas exportadoras está baseado na ideia de exportação como um processo de aprendizado que permite às firmas exportadoras realizar inovações, aprimorando, como resultado, as suas produtividades. 
Como frisado anteriormente, o presente trabalho pretende reunir informações a fim de verificar a existência ou não de diferenças de produtividade na indústria brasileira ao nível das firmas. Verificada a existência de diferenciais de produtividade, e com base nos princípios teóricos acima descritos, objetiva-se testar as seguintes hipóteses:

Pretende-se, em primeiro lugar, verificar se as diferenças de produtividade no caso das firmas brasileiras refletem processos de seleção e/ou processos de aprendizado no comércio internacional. Processos de autosseleção na entrada implicam diferenças de produtividade entre firmas exportadoras e não exportadoras antes do ingresso daquelas no comércio internacional. Por outro lado, a seleção na saída do mercado implica que a produtividade das firmas que continuam no comércio é maior do que a produtividade das firmas que saem dos mercados de exportação.

Pretende-se verificar se o processo de aprendizado no comércio internacional explica diferenças de produtividade. Caso essa hipótese seja válida, então esperar-se-ia que diferenças de níveis de produtividade entre firmas exportadoras e não exportadoras deveriam aumentar depois da entrada das firmas exportadoras no mercado internacional.

O teste das hipóteses acima mencionadas será feito comparando não apenas os níveis de produtividade, mas também as taxas de crescimento de produtividade para firmas que tiveram participação no mercado estrangeiro e no mercado doméstico no período.

\subsection{Metodologia}

A fim de conhecer melhor a produtividade das firmas na indústria de transformação brasileira, pretende-se comparar a função de distribuição cumulativa da produtividade total dos fatores, e de forma alternativa para a produtividade do trabalho, para quatro grupos diferentes de firmas: exportadoras, não exportadoras, exportadoras entrando no mercado internacional (no primeiro ano da amostra) e exportadoras saindo do mercado internacional. Testes devem ser realizados a fim de se saber se a transição de uma firma de mercado doméstico para exportadora é consistente com as diferenças de produtividade. Seguindo procedimento desenvolvido por Delgado, Fariñas e Ruano (2002), essas distribuições cumulativas de produtividade serão ordenadas, utilizando o princípio de dominância estocástica de primeira ordem, e as diferenças estatisticamente testadas utilizando os testes não paramétricos de Kolmogorov - Smirnov. A seguir, será feita uma exposição resumida do teste Kolmogorov - Smirnov. 
Considere A e B como sendo a função de distribuição cumulativa de produtividade referente a dois grupos de firmas que estão sendo comparadas, digamos firmas exportadoras e firmas não exportadoras. Então, a dominância estocástica de primeira ordem de A relativa a B é definida pela seguinte condição:

$A(x)-B(x) \leq 0$ uniformemente para $x \in R$ e $A(x)-B(x)<0$ para algum $x$.

Seja $x_{1}, x_{2}, \ldots, x_{n}$, uma amostra aleatória de tamanho $n$, referente a um grupo de firmas da função de distribuição A, e seja $x_{n+1}, x_{n+2}, \ldots, x_{n+m}$. uma amostra aleatória de tamanho $m$, independente do primeiro grupo, e referente a um grupo de firmas da distribuição $\mathrm{B}$, onde $x_{i}$ denota o nível de produtividade da firma $i$.

O trabalho visa realizar os seguintes testes de hipóteses:

(1) $H_{0}: A(x)-B(x)=0$, para todo $x \in R$ vs. $\mathrm{H}_{1}: A(x)-B(x) \neq 0$ para algum $x \in$ $R$ pode ser rejeitado.

(2) $H_{0}: A(x)-B(x) \leq 0$, para todo $x \in R$ vs. $H_{1}: A(x)-B(x)>0$ para algum $x \in$ $R$ não pode ser rejeitado.

Em outras palavras, o teste (1) permite determinar se as duas distribuições da produtividade para categorias de firmas são idênticas ou não. Por sua vez, o teste (2) permite verificar se uma distribuição domina ou não a outra. Caso a hipótese (1) seja rejeitada enquanto a hipótese (2) não for rejeitada, isso significa que a distribuição da produtividade de uma determinada categoria de firma domina estocasticamente a distribuição da produtividade de outra classificação de firma. No presente caso empírico, pretende-se testar a diferença de produtividade entre firmas exportadoras e não exportadoras.

A estatística $p$ do teste Kolmogorov-Smirnov para o teste de uma cauda foi calculada da seguinte forma: ${ }^{2}$

$$
p-\text { value }_{\text {one-sided }}=t \sum_{j=0}^{[n(1-t)]}\left(\begin{array}{l}
n \\
j
\end{array}\right)\left(1-t-\frac{j}{n}\right)^{n-j}\left(t+\frac{j}{n}\right)^{j-1}
$$

Para obter o valor $p$ do teste de duas caudas, basta multiplicar o valor $p$ do teste de uma cauda por 2 (dois). Na fórmula acima, $t$ é a estatística teste - maior distância entre diferentes distribuições. No somatório, $j$ vai de 0 (zero) até $n(1-t)$, em que $n$ é o número de observações e $n(l-t)$ é o supremo (inteiro) menor ou igual a $n(l-t)$.

2 Para maiores detalhes sobre o teste Kolmogorov-Smirnov, ver Conover (1999). 
O valor aproximado do teste de uma cauda $p$-value é dado por Conover (1999):

$$
\begin{aligned}
& 90 \%=1.22 / \sqrt{n} \\
& 95 \%=1.36 / \sqrt{n} \\
& 99 \%=1.63 / \sqrt{n}
\end{aligned}
$$

\section{RESULTADOS OBTIDOS}

\subsection{Dados Utilizados}

No Brasil não se dispõe de uma única fonte de informações que reúna dados das variáveis na indústria de transformação ao nível de firmas. Desta forma, a realização deste trabalho exigiu a combinação e compatibilização de 3 (três) fontes diferentes de dados: microdados da "Pesquisa Industrial Anual" (PIA) da Fundação Instituto Brasileiro de Geografia e Estatística (FIBGE), a base de dados da Secretaria de Comércio Exterior (SECEX) e a Relação Anual de Informações Sociais (RAIS) do Ministério do Trabalho (MTE). Foram selecionadas as firmas pertencentes à Classificação Nacional de Atividades Econômicas (CNAE) com dígitos 15 a 36. O período em análise compreende os anos de 1997 a 2003.

Diversas categorias de firmas exportadoras foram consideradas segundo a participação das mesmas no mercado exportador durante o período de análise. Precisamente, quatro categorias foram criadas: 1) firmas que sempre exportaram no período; 2) firmas que entraram no mercado exportador no início do período e que não saíram; 3) firmas que saíram do mercado exportador e que não voltaram. Identificou-se, da mesma forma, as firmas que nunca exportaram para o exterior durante o período 1997-2003 (a quarta categoria). Os testes realizados na próxima subseção comparam o desempenho das produtividades das diferentes categorias de empresas.

Ademais, os resultados apresentados foram divididos em duas categorias de tamanho: firmas de pequeno porte (firmas que têm entre 30 e 99 empregados) e firmas de grande porte (firmas com mais de 500 empregados). A fim de mostrar a importância relativa de firmas de diferente tamanho nas exportações totais do Brasil, na Tabela 1 apresentam-se as tendências ao longo do tempo das exportaçóes das firmas por diferentes categorias de tamanho. Os dados mostram um aumento na participação das firmas de grande porte e uma queda na participação das exportações das 
firmas de médio e pequeno porte. A participação das firmas de grande porte cresceu paulatinamente entre 1997 e 2003 . A participação das firmas de médio porte caiu de 19,5\% em 1997 para 16,3\% em 2003. Por outro lado, as firmas de pequeno porte perderam quase $1 \%$ de participação das exportações totais do Brasil no período analisado.

\section{TABELA I- PARTICIPAÇÃO NAS EXPORTAÇÓES TOTAIS SEGUNDO TA- MANHO DE FIRMAS, PERÍODO 1997 - 2003}

\begin{tabular}{lccccccc}
\hline & \multicolumn{7}{c}{ Participação nas exportações totais do Brasil } \\
\cline { 2 - 8 } Tipo de firma & 1997 & 1998 & 1999 & 2000 & 2001 & 2002 & 2003 \\
\hline Grande porte & $76.5 \%$ & $76.6 \%$ & $75.6 \%$ & $76.5 \%$ & $77.8 \%$ & $79.5 \%$ & $80.6 \%$ \\
Médio porte & $19.5 \%$ & $19.4 \%$ & $20.4 \%$ & $19.8 \%$ & $18.0 \%$ & $17.0 \%$ & $16.3 \%$ \\
Pequeno porte & $4.0 \%$ & $4.0 \%$ & $4.0 \%$ & $3.7 \%$ & $4.2 \%$ & $3.5 \%$ & $3.1 \%$ \\
\hline
\end{tabular}

Fonte: SECEX/MDIC, RAIS/MTE, Cálculo dos autores.

Realizou-se também a comparação das diversas categorias de firmas para as variáveis de produtividade (total dos fatores e do trabalho). Assim, neste trabalho a análise está sendo feita com base em dois conceitos de produtividade: produtividade total dos fatores (PTF) e produtividade do trabalho (PL). ${ }^{3}$ A PTF foi calculada com base no resíduo de Solow (1957). A PTF corresponde ao resíduo de regressão da função de produção Cobb-Douglas estimado ao nível de cada firma. ${ }^{4}$ Por outro lado, a PL corresponde à produção física total dividida pelo número de trabalhadores ocupados na firma, da Pesquisa Industrial Mensal-Dados Gerais (PIM-DG).

Apesar de esses dados serem os mais utilizados na mensuração da produtividade no Brasil, alguns economistas colocam dúvidas sobre a representatividade das séries históricas e sobre o método de cálculo. Argumenta-se, por exemplo, que as pesquisas industriais elaboradas pela FIBGE têm perdido representatividade ao longo do tempo. ${ }^{5}$ Alega-se também que existem problemas para adequar a produção física e as

3 Na literatura, diversos índices têm sido sugeridos a fim de mensurar produtividade. Caves,. Christensen e Diewert (1982) desenvolveram um índice multilateral que reúne propriedades de transitividade e tem a vantagem de que para seu cálculo não é necessária a estimação de funções de produção. Esse índice, com algumas modificações, foi utilizado por Aw. B. Y., S. Chung e M. J. Roberts (2000) e Delgado, Fariñas e Ruano (2002). Solow (1957) desenvolveu uma medida de produtividade muito usada na literatura, chamada de produtividade multifatorial ou total, e que depende de duas hipóteses: rendimentos constantes de escala e mercados competitivos.

4 As variáveis utilizadas na regressão para obtenção dos resíduos foram o emprego total e o consumo de energia (proxy para capital físico). Controlou-se também pelo setor da CNAE em 2 dígitos. A variável dependente empregada foi o VTI (valor de transformação) de cada firma.

5 Argumenta-se que a terceirização e a substituição de insumos de origem nacional por importados podem distorcer o valor adicionado correto. Entretanto, Bonelli e Fonseca (1998) mostraram que o fenômeno da terceirização não é tão intenso quanto se imagina. Por outro lado, o questionamento sobre a perda de representatividade da Pesquisa Industrial não parece ser tão evidente quanto se imagina. Bonelli 
horas pagas como proxies do valor adicionado e das horas trabalhadas. Na verdade, se está admitindo que ao longo do tempo os preços relativos, a estrutura de mercado e a qualidade dos bens têm permanecido constante, o que pode não ser verdade na prática. Também a PIM-DG pesquisa horas pagas, e não as horas trabalhadas que é o correto quando se tenta mensurar a produtividade. A diferença seriam as horas pagas e que não foram trabalhadas, a exemplo dos períodos de férias dos trabalhadores. Alguns autores argumentam, porém, que na verdade as duas variáveis parecem apresentar evolução histórica semelhante. Por outro lado, mudanças na qualificação da mão de obra não são levadas em conta no índice de pessoal ocupado. Assim, os resultados a serem apresentados neste trabalho devem ser vistos com o devidos cuidado, levando em consideração as limitações anteriormente apontadas sobre os dados.

Como dito anteriormente, o painel construído refere-se ao período de 1997 a 2003. O banco de dados inclui firmas da indústria da transformação com número de empregados superior a $30 \mathrm{em}$ algum ano do período 1997-2003. Vale ressaltar que este critério inclui tanto firmas que exportaram quanto firmas que nunca exportaram durante o período. Utilizamos somente o estrato certo (a parte censitária) da Pesquisa Industrial Anual, i.e., somente firmas com mais de 30 empregados. Com isto, desvia-se de questões relacionadas ao peso da amostra (uma das questões mais debatidas na PIA).

\subsection{Resultados do Teste Não Paramétrico de Kolmogorov-Smirnov}

Esta subseção inicia a investigação empírica pelas diferenças de produtividade entre firmas que sempre foram exportadoras e firmas que nunca foram exportadoras. A Tabela 2 apresenta o teste de diferenças de produtividade para o conjunto de todas as firmas durante o período considerado, 1997-2003. A Tabela 3 apresenta o mesmo teste, porém para o conjunto das firmas de grande porte; a Tabela 4, por sua vez, mostra o teste de diferenças de produtividade para o conjunto de firmas de pequeno porte. A fim de testar a dominância estocástica são usadas funções de distribuição cumulativas para diversas categorias de firmas: o conjunto inteiro das empresas, as de grande porte e as de pequeno porte. As Tabelas 2, 3 e 4 mostram o teste Kolmogorov-Smirnov com base na medida de produtividade total dos fatores. Ademais, as Tabelas A.1, A.2 e A.3, apresentadas no Anexo, mostram os mesmos testes, utilizando desta vez a medida de produtividade do trabalho. Primeiramente, os resultados das tabelas supracitadas mostram que há uma diferença na distribuição

e Fonseca (1998) mostram, por exemplo, que as taxas de mudança do pessoal ocupado segundo a Pesquisa Industrial e do pessoal ocupado com carteira assinada, segundo a pesquisa mensal de emprego da FIBGE, apresentam resultados muito semelhantes. 
da produtividade entre empresas que sempre exportaram e as que nunca venderam seus produtos no mercado internacional. De uma forma geral, os resultados das tabelas mostram, de maneira similar, maiores níveis de produtividade para as firmas exportadoras do que para as firmas não exportadoras (não se rejeita a hipótese nula de diferença de produtividade favorável às firmas exportadoras). Isto significa que há uma dominância estocástica de primeira ordem no que tange à produtividade das firmas exportadoras.

TABELA 2 - TESTE ESTATÍSTICO DAS DIFERENÇAS DE PTF ENTRE FIRMAS EXPORTADORAS E NÃO EXPORTADORAS - CONJUNTO DE TODAS AS FIRMAS

\begin{tabular}{|c|c|c|c|c|c|c|}
\hline \multirow[t]{3}{*}{ Ano } & \multicolumn{6}{|c|}{ Firmas sempre exportadoras vs. Firmas nunca exportadoras } \\
\hline & \multicolumn{2}{|c|}{$\begin{array}{l}\text { Número de } \\
\text { observações }\end{array}$} & \multicolumn{2}{|c|}{$\begin{array}{l}\text { Igualdade da } \\
\text { distribuição }\end{array}$} & \multicolumn{2}{|c|}{$\begin{array}{c}\text { Diferença favorável às } \\
\text { exportadoras }\end{array}$} \\
\hline & Exportadoras & Não exportadoras & Estatística & $p$-value & Estatística & $p$-value \\
\hline 1997 & 3167 & 11444 & 0,1921 & 0,000 & 0,0004 & 0,999 \\
\hline 1998 & 3307 & 12286 & 0,1834 & 0,000 & 0,0009 & 0,996 \\
\hline 1999 & 3330 & 12540 & 0,2320 & 0,000 & 0,0006 & 0,998 \\
\hline 2000 & 3301 & 12884 & 0,2208 & 0,000 & 0,0010 & 0,994 \\
\hline 2001 & 3306 & 13920 & 0,2325 & 0,000 & 0,0008 & 0,997 \\
\hline 2002 & 3345 & 15092 & 0,2593 & 0,000 & 0,0002 & 0,999 \\
\hline 2003 & 3302 & 16165 & 0,2420 & 0,000 & 0,0003 & 0,999 \\
\hline Todos os anos & 23058 & 94331 & 0,2208 & 0,000 & 0,0003 & 0,998 \\
\hline
\end{tabular}

Fonte: Cálculo dos autores. 
TABELA 3 - TESTE ESTATÍSTICO DAS DIFERENÇAS DE PTF ENTRE FIRMAS EXPORTADORAS E NAOO EXPORTADORAS - FIRMAS DE GRANDE PORTE

\begin{tabular}{|c|c|c|c|c|c|c|}
\hline \multirow[t]{3}{*}{ Ano } & \multicolumn{6}{|c|}{ Firmas de grande porte sempre exportadoras vs. Firmas de grande porte nunca exportadoras } \\
\hline & \multicolumn{2}{|c|}{$\begin{array}{l}\text { Número de } \\
\text { observações }\end{array}$} & \multicolumn{2}{|c|}{$\begin{array}{l}\text { Igualdade da } \\
\text { distribuição }\end{array}$} & \multicolumn{2}{|c|}{$\begin{array}{c}\text { Diferença favorável às } \\
\text { exportadoras }\end{array}$} \\
\hline & Exportadoras & Não exportadoras & Estatística & $p$-value & Estatística & $p$-value \\
\hline 1997 & 723 & 177 & 0,1248 & 0,012 & 0,0694 & 0,256 \\
\hline 1998 & 686 & 141 & 0,1313 & 0,018 & 0,1215 & 0,032 \\
\hline 1999 & 679 & 131 & 0,1516 & 0,007 & 0,0244 & 0,878 \\
\hline 2000 & 712 & 120 & 0,1698 & 0,003 & 0,0095 & 0,982 \\
\hline 2001 & 740 & 127 & 0,1863 & 0,001 & 0,0074 & 0,988 \\
\hline 2002 & 757 & 141 & 0,1784 & 0,001 & 0,0610 & 0,413 \\
\hline 2003 & 767 & 167 & 0,2295 & 0,000 & 0,0160 & 0,932 \\
\hline Todos os anos & 5064 & 1004 & 0,1563 & 0,000 & 0,0107 & 0,827 \\
\hline
\end{tabular}

Fonte: Cálculo dos autores.

TABELA 4 - TESTE ESTATÍSTICO DAS DIFERENÇAS DE PTF ENTRE FIRMAS EXPORTADORAS E NÃO EXPORTADORAS - FIRMAS DE PEQUENO PORTE

\begin{tabular}{|c|c|c|c|c|c|c|}
\hline \multirow[t]{3}{*}{ Ano } & \multicolumn{6}{|c|}{ Firmas de pequeno porte sempre exportadoras vs. Firmas de pequeno porte nunca exportadoras } \\
\hline & \multicolumn{2}{|c|}{$\begin{array}{l}\text { Número de } \\
\text { observações }\end{array}$} & \multicolumn{2}{|c|}{$\begin{array}{l}\text { Igualdade da } \\
\text { distribuição }\end{array}$} & \multicolumn{2}{|c|}{$\begin{array}{c}\text { Diferença favorável às } \\
\text { exportadoras }\end{array}$} \\
\hline & Exportadoras & Não exportadoras & Estatística & $p$-value & Estatística & $p$-value \\
\hline 1997 & 915 & 7671 & 0,3347 & 0,000 & 0,0004 & 1,000 \\
\hline 1998 & 995 & 7900 & 0,3532 & 0,000 & 0,0009 & 0,999 \\
\hline 1999 & 980 & 8240 & 0,4001 & 0,000 & 0,0001 & 1,000 \\
\hline 2000 & 929 & 9013 & 0,3998 & 0,000 & 0,0001 & 1,000 \\
\hline 2001 & 930 & 9786 & 0,3928 & 0,000 & 0,0015 & 0,996 \\
\hline 2002 & 960 & 10522 & 0,3820 & 0,000 & 0,0009 & 0,998 \\
\hline 2003 & 925 & 11057 & 0,3794 & 0,000 & 0,0005 & 0,999 \\
\hline Todos os anos & 6634 & 64189 & 0,3722 & 0,000 & 0,0001 & 1,000 \\
\hline
\end{tabular}

Fonte: Cálculo dos autores. 
Conforme verificado nas Tabelas 4 e A.3, essas diferenças de produtividade parecem ser mais acentuadas para as firmas da categoria de firmas de pequeno porte. No caso das firmas de pequeno porte, a hipótese nula de igualdade entre ambas as distribuições pode ser rejeitada ao nível de significância de $0,1 \%$ para todos os anos do período. Pode-se concluir, portanto, que a distribuição de produtividade das firmas de pequeno porte exportadoras domina estocasticamente a distribuição de produtividade das firmas de pequeno porte não exportadoras. ${ }^{6}$

Verificada a diferença de produtividade entre firmas exportadoras e não exportadoras, a análise a seguir está voltada para o teste das possíveis causas dos diferenciais de produtividade entre tais categorias de firmas. Examinar-se-á se a transição entre o mercado doméstico e o mercado estrangeiro é consistente com determinadas diferenças de produtividade. Pretende-se saber se o maior nível de produtividade das firmas exportadoras se deve ou não a processos de seleção, sendo que esta seleção pode acontecer tanto na entrada quanto na saída das firmas do mercado de exportação. Seleção na entrada significa que apenas firmas de alta produtividade entram no comércio internacional. Por outro lado, seleção na saída significa que firmas exportadoras de baixa produtividade são potencialmente obrigadas a abandonar $\mathrm{o}$ mercado de exportação.

A fim de verificar ou não a hipótese de seleção na entrada, dois conjuntos de firmas são confrontados: firmas não exportadoras e firmas entrantes no mercado de exportação. Para definir o grupo de firmas entrantes considera-se o ano de 1997 como referência. Firmas entrantes no mercado de exportação são aquelas que não exportaram em 1997 e que exportaram em todos os anos do período 1998-2003. Firmas que não comercializaram seus produtos no mercado internacional definem as não exportadoras. $\mathrm{O}$ teste realizado compara a produtividade das firmas no ano de 1997, ou seja, antes da entrada das "firmas entrantes" no mercado exportador. A Tabela 5 compara a distribuição da produtividade total de fatores para os dois grupos de firmas: entrantes e não exportadoras. A referida tabela apresenta o teste Kolmogorov-Smirnov para o conjunto de todas as firmas, para o grupo de firmas de pequeno porte e para o grupo de firmas de grande porte. A Tabela A.4, apresentada no Anexo, demonstra o mesmo teste, porém desta vez utilizando o conceito de produtividade do trabalho. Os resultados da Tabela 5 mostram que para o conjunto das firmas, e também para o grupo de firmas de pequeno porte, pode-se rejeitar a hipótese de igualdade das distribuições a menos de $1 \%$ de significância. Por outro

6 Estimaram-se, também, testes de diferenças de produtividade entre firmas sempre exportadoras e firmas nunca exportadoras segundo diferentes mercados de exportação. Foram selecionados os mercados de exportação de Estados Unidos, Argentina, China e a Índia para realizar os testes. Os resultados, não apresentados no presente trabalho, confirmam o que foi verificado anteriormente, ou seja, as firmas exportadoras apresentam maior nível de produtividade do que as firmas não exportadoras, independentemente do mercado de destino da exportação. 
lado, para o conjunto de firmas de grande porte não é possível rejeitar a hipótese de igualdade das distribuições. Verifica-se que, para o caso geral e da amostra de pequenas empresas, não se rejeita a hipótese de diferença de produtividade favorável às firmas entrantes. Então, verifica-se o processo de seleção na entrada. Os resultados da Tabela A.4, em geral, confirmam a hipótese de seleção das firmas na entrada no mercado de exportação.

Outra forma de apresentar os resultados é através da análise gráfica. Assim, nas Figuras 1 e 2 apresenta-se a distribuição cumulativa da PTF e de PT para o grupo de firmas entrantes e para o grupo de firmas não exportadoras. Nota-se que a distribuição acumulada da produtividade total dos fatores e do trabalho das firmas entrantes está sempre à direita da distribuição das empresas que nunca exportaram. As figuras confirmam o que os dados das Tabelas 5 e A.4 mostram, ou seja, é rejeitada a hipótese nula de igualdade da PTF e da PT entre as firmas entrantes e as não exportadoras.

\section{FIGURA 1 - PTF DAS FIRMAS ENTRANTES E DAS FIRMAS NÃO EXPOR-} TADORAS - CONJUNTO DE TODAS AS FIRMAS

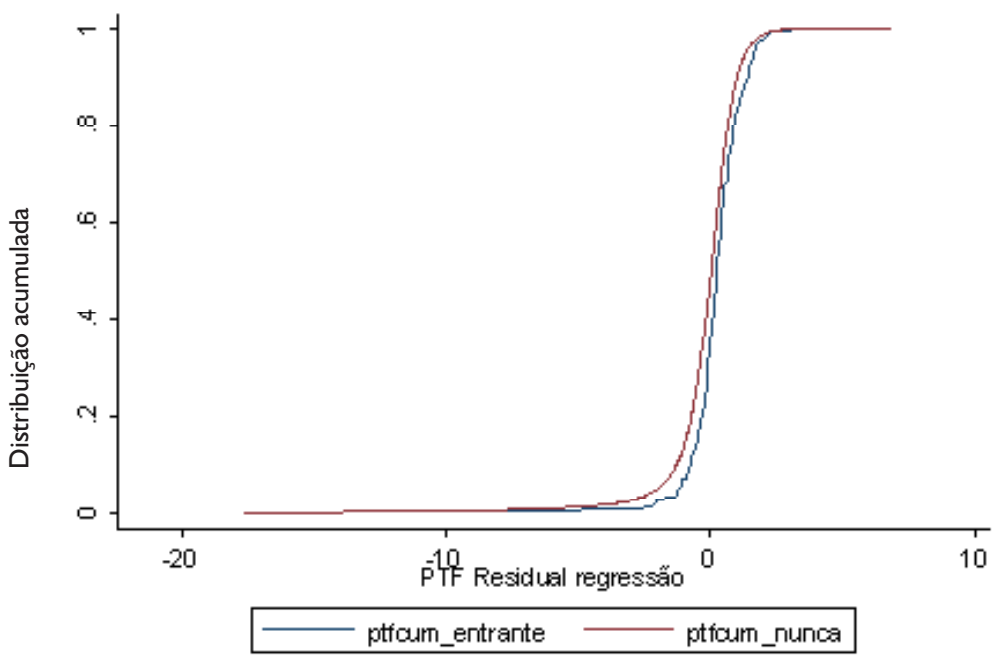

Fonte: IBGE/ Diretoria de Pesquisas, Coordenação de Indústria, PIA, 1997-2003.

Elaboração: IPEA/DISET a partir da transformação dos dados obtidos na fonte e com incorporação de dados da Secex/MDIC e Rais/MTE. 


\section{FIGURA 2 - PL DAS FIR MAS ENTRANTES E DAS FIRMAS NÃO EXPORTA-} DORAS - CONJUNTO DE TODAS AS FIRMAS

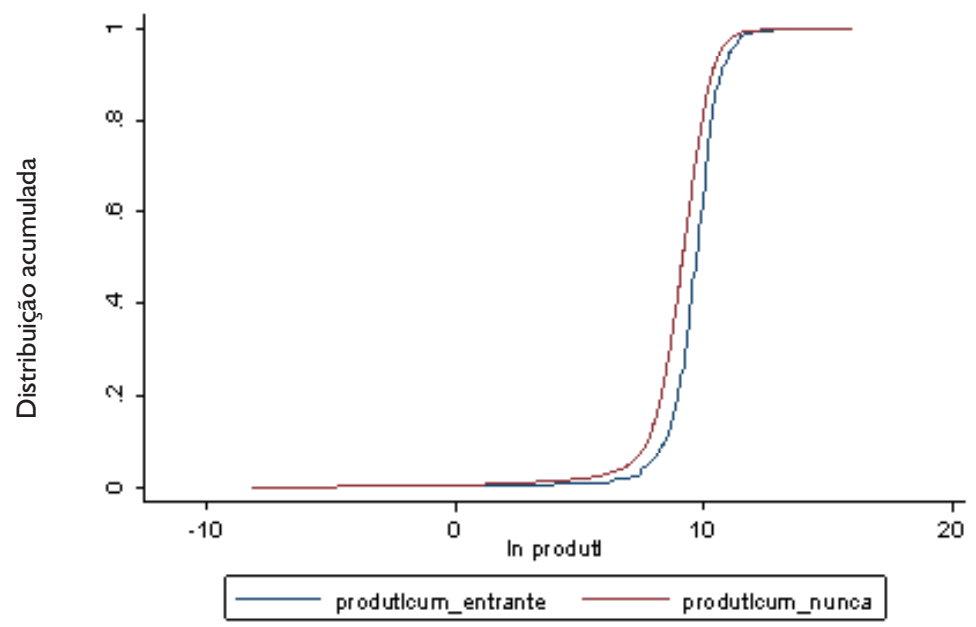

Fonte: IBGE/ Diretoria de Pesquisas, Coordenação de Indústria, PIA, 1997-2003.

Elaboração: IPEA/DISET a partir da transformação dos dados obtidos na fonte e com incorporação de dados da Secex/MDIC e Rais/MTE.

TABELA 5 - TESTE ESTATÍSTICO COMPARATIVO ENTRE A DISTRIBUIÇÃO DE PTF DAS FIRMAS ENTRANTES E NÃO EXPORTADORAS - CONJUNTO DAS FIRMAS, FIRMAS DE PEQUENO PORTE E FIRMAS DE GR ANDE PORTE

\begin{tabular}{|c|c|c|c|c|c|c|}
\hline \multirow[t]{2}{*}{ Ano $=1997$} & \multicolumn{2}{|c|}{$\begin{array}{l}\text { Número de } \\
\text { observações }\end{array}$} & \multicolumn{2}{|c|}{$\begin{array}{l}\text { Igualdade da } \\
\text { distribuição }\end{array}$} & \multicolumn{2}{|c|}{$\begin{array}{c}\text { Diferença favorável às } \\
\text { exportadoras }\end{array}$} \\
\hline & Entrantes & Não exportadoras & Estatística & $p$-value & Estatística & $p$-value \\
\hline $\begin{array}{l}\text { Firmas entrantes vs. Firmas nunca } \\
\text { exportadoras }\end{array}$ & 258 & 11444 & 0,1649 & 0,0000 & 0,0008 & 1,0000 \\
\hline $\begin{array}{l}\text { Firmas entrantes de pequeno porte } \\
\text { vs. Firmas de pequeno porte nunca } \\
\text { exportadoras }\end{array}$ & 145 & 7671 & 0,2383 & 0,0000 & 0,0032 & 0,9970 \\
\hline $\begin{array}{l}\text { Firmas entrantes de grande porte } \\
\text { vs. Firmas de grande porte nunca } \\
\text { exportadoras }\end{array}$ & 10 & 177 & 0,2841 & 0,4300 & 0,1477 & 0,6620 \\
\hline
\end{tabular}

Fonte: Cálculo dos autores. 
A fim de testar a hipótese de seleção na saída é feita uma comparação entre a distribuição de produtividade ex-ante das firmas que deixam o mercado exportador e das firmas que nunca exportaram. O teste estatístico relativo à hipótese de seleção na saída é apresentado nas Tabelas 6 e A.5. Na Tabela 6, o teste é realizado com base no conceito de produtividade total dos fatores, e na Tabela A.5 com base no conceito de produtividade do trabalho. Conforme verificado na Tabela 6 , a hipótese de seleção na saída não pode ser rejeitada ao nível de significância de 0,1 para todo o período considerado. Os resultados da Tabela A.5, de um modo geral, confirmam esse resultado, embora para o grupo de firmas de grande porte o nível de significância exigido seja um pouco maior. Em resumo, podemos concluir que as firmas que saem do mercado exportador têm em média maior nível de produtividade que as firmas que nunca foram exportadoras. Fica, portanto, confirmada a hipótese de que as diferenças de produtividade das firmas brasileiras refletem processos de seleção no comércio internacional.

Outra hipótese levantada inicialmente a fim de explicar as diferenças de produtividade entre firmas exportadoras e não exportadoras refere-se ao processo de aprendizado no comércio internacional. Pretende-se saber se a entrada de firmas no mercado de exportação resulta em maiores níveis de crescimento de produtividade para essas firmas. A fim de testar essa hipótese é calculada a taxa de crescimento da produtividade para as firmas exportadoras e para as firmas não exportadoras. O resultado do teste de igualdade das duas distribuições é apresentado nas Tabelas 7 e A.6. O teste é feito levando em conta a totalidade de empresas, as firmas de pequeno e as de grande porte. Os resultados apresentados nessas tabelas mostram que se rejeita a hipótese de igualdade das duas distribuições, entretanto, não se pode dizer que há uma diferença favorável para as firmas exportadoras, logo, aparenta não existir processos de aprendizado no comércio internacional brasileiro. ${ }^{7} \mathrm{O}$ crescimento da produtividade das firmas exportadoras e não exportadoras não parece ser estatisticamente diferente.

7 Esse resultado também foi encontrado para outros países. Ver Delgado, Fariñas e Ruano (2002). 
TABELA 6 - TESTE ESTATÍSTICO COMPARATIVO ENTRE A DISTRIBUIÇAOO DE PTF EX-ANTE DAS FIRMAS QUE DEIXAM O MERCADO EXPORTADOR E DAS FIRMAS QUE NUNCA EXPORTARAM - TODOS OS ANOS

\begin{tabular}{|c|c|c|c|c|c|c|}
\hline & \multicolumn{6}{|c|}{ Firmas "exiting" vs. Firmas nunca exportadoras } \\
\hline & \multicolumn{2}{|r|}{$\begin{array}{l}\text { Número de } \\
\text { Observações }\end{array}$} & \multicolumn{2}{|c|}{$\begin{array}{l}\text { Igualdade da } \\
\text { Distribuição }\end{array}$} & \multicolumn{2}{|c|}{$\begin{array}{l}\text { Diferença favorável às } \\
\text { exportadoras }\end{array}$} \\
\hline & Exiting & Nunca exportadoras & Estatística & $p$-value & Estatística & $p$-value \\
\hline $\begin{array}{l}\text { Firmas "exiting" vs. Firmas nunca } \\
\text { exportadoras }\end{array}$ & 1532 & 94331 & 0,0987 & 0,0000 & 0,0006 & 0,9990 \\
\hline $\begin{array}{l}\text { Firmas de grande porte "exiting" } \\
\text { vs. Firmas de grande porte nunca } \\
\text { exportadoras }\end{array}$ & 170 & 1004 & 0,0943 & 0,1060 & 0,0291 & 0,7560 \\
\hline $\begin{array}{l}\text { Firmas de pequeno porte "exiting" } \\
\text { vs. Firmas de pequeno porte nunca } \\
\text { exportadoras }\end{array}$ & 620 & 64189 & 0,2043 & 0,0000 & 0,0006 & 0,9990 \\
\hline
\end{tabular}

Fonte: Cálculo dos autores.

TABELA 7 - TESTE ESTATÍSTICO DA TAXA DE CRESCIMENTO DE PTF PARA AS FIRMAS EXPORTADORAS E PARA AS FIRMAS NÃO EXPORTADORAS

\begin{tabular}{|c|c|c|c|c|c|c|}
\hline \multirow[t]{2}{*}{ Todos os anos } & \multicolumn{2}{|c|}{$\begin{array}{l}\text { Número de } \\
\text { observações }\end{array}$} & \multicolumn{2}{|c|}{$\begin{array}{l}\text { Igualdade da } \\
\text { distribuição }\end{array}$} & \multicolumn{2}{|c|}{$\begin{array}{c}\text { Diferença favorável às } \\
\text { exportadoras }\end{array}$} \\
\hline & Exportadoras & Não exportadoras & Estatística & $p$-value & Estatística & $p$-value \\
\hline $\begin{array}{l}\text { Firmas sempre exportadoras vs. } \\
\text { Firmas nunca exportadoras }\end{array}$ & 23058 & 94331 & 0,0969 & 0,0000 & $-0,0365$ & 0,0120 \\
\hline $\begin{array}{l}\text { Firmas sempre exportadoras } \\
\text { de grande porte vs. Firmas de } \\
\text { grande porte nunca exportadoras }\end{array}$ & 5064 & 1004 & 0,2067 & 0,0000 & $-0,0346$ & 0,7900 \\
\hline $\begin{array}{l}\text { Firmas sempre exportadoras } \\
\text { de pequeno porte vs. Firmas } \\
\text { de pequeno porte nunca } \\
\text { exportadoras }\end{array}$ & 6634 & 64189 & 0,1074 & 0,0000 & $-0,0106$ & 0,8930 \\
\hline
\end{tabular}

Fonte: Cálculo dos autores. 
FIGURA 3 - TAXA DE CRESCIMENTO DA PTF DAS FIR MAS SEMPRE EXPORTADORAS E DAS FIRMAS NUNCA EXPORTADORAS

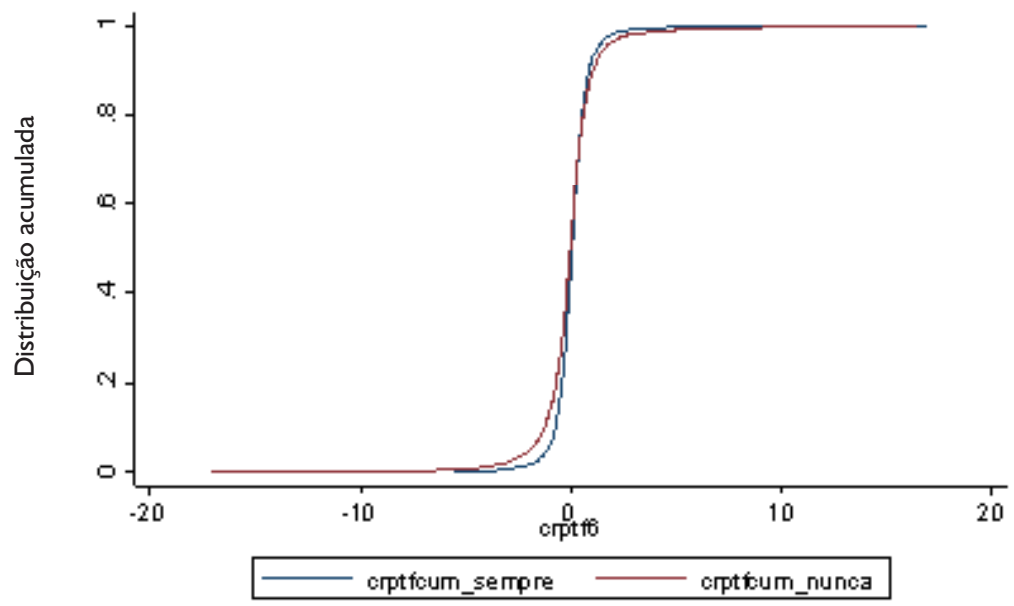

Fonte: IBGE/ Diretoria de Pesquisas, Coordenação de Indústria, PIA, 1997-2003.

Elaboração: IPEA/DISET a partir da transformação dos dados obtidos na fonte e com incorporação de dados da Secex/MDIC e Rais/MTE

FIGURA 4 - TAXA DE CRESCIMENTO DA PL DAS FIRMAS SEMPRE EXPORTADORAS E DAS FIRMAS NUNCA EXPORTADORAS

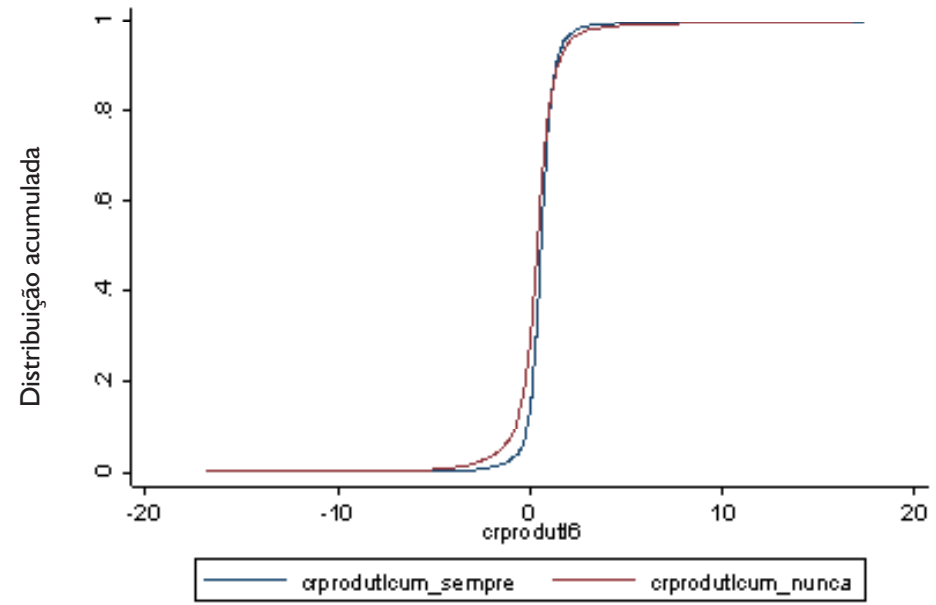

Fonte: IBGE/ Diretoria de Pesquisas, Coordenação de Indústria, PIA, 1997-2003.

Elaboração: IPEA/DISET a partir da transformação dos dados obtidos na fonte e com incorporação de dados da Secex/MDIC e Rais/MTE 
Nas Figuras 3 e 4, apresenta-se a distribuição cumulativa da taxa de crescimento da PTF e da PT, para as firmas exportadoras e para as não exportadoras. As figuras verificam o que os dados das Tabelas 7 e A.6 mostraram, ou seja, não é possível rejeitar a hipótese nula de igualdade da taxa de crescimento da produtividade das firmas exportadoras e das não exportadoras, confirmando portanto a hipótese de não aprendizado no mercado exportador.

Um exercício complementar foi realizado para averiguar a diferença de produtividade das firmas sempre exportadoras. A ideia é comparar a produtividades das firmas exportadoras de acordo com o país de destino das exportações. Comparar a produtividade de firmas que exportam, por exemplo, para os Estados Unidos (EUA) e a produtividade das firmas que exportam para outros países pode ser um exercício útil a fim de averiguar se o comércio internacional seleciona as firmas exportadoras. Como os EUA seriam um mercado mais competitivo do que a média dos mercados mundiais, poder-se-ia esperar que as firmas exportadoras para os EUA fossem mais produtivas. Da mesma maneira, as empresas que exportam para destinos mais competitivos deveriam sempre buscar um maior crescimento da produtividade. Em outras palavras, o efeito aprendizado do comércio internacional poderia ser mais intenso em mercados mais competitivos. Foram realizados, portanto, testes de diferenças de produtividade entre firmas exportadoras para os EUA e firmas exportadoras para outros mercados internacionais. Precisamente, foi selecionado o mercado de exportação dos EUA a fim de realizar os referidos testes.

Os resultados, apresentados nas Tabelas 8 e A.7, mostram que há uma diferença na distribuição da produtividade entre empresas que exportam para os Estados Unidos e as que venderam seus produtos em outros mercados. Ademais, os resultados apontam maiores níveis de produtividade para as firmas exportadoras para os EUA do que para outros destinos das firmas exportadoras. Em outras palavras, não se rejeita a hipótese nula de diferença de produtividade favorável às firmas exportadoras para os EUA. Desta forma, as estimativas apontam evidências sobre a seleção de firmas mais produtivas para exportar para um mercado mais competitivo, ilustrado como o dos Estados Unidos.

Com relação ao maior aprendizado de firmas exportadoras para os EUA, as Tabelas 9 e A.8 mostram que a hipótese de igualdade de crescimento da produtividade entre as firmas (exportadoras para os EUA e outras exportadoras) não pode ser rejeitada (para o caso de produtividade total dos fatores). Mesmo quando a hipótese de igualdade é rejeitada, como no caso do grupo de firmas de maior porte e de menor porte, não é possível afirmar que haja uma diferença favorável para as firmas exportadoras para os EUA. Resultados que suportariam um maior aprendizado em 
mercados mais competitivos, como os EUA, não são evidentes pelos critérios estatísticos utilizados.

TABELA 8 - TESTE ESTATÍSTICO COMPARATIVO ENTRE A DISTRIBUIÇAO DE PTF DAS FIRMAS EXPORTADORAS PARA OS EUA E EXPORTADORAS PARA OUTROS MERCADOS INTERNACIONAIS - CONJUNTO DAS FIRMAS, FIRMAS DE PEQUENO PORTE E FIRMAS DE GRANDE PORTE

\begin{tabular}{|c|c|c|c|c|c|c|}
\hline & \multicolumn{2}{|c|}{ Número de Observações } & \multicolumn{2}{|c|}{ Igualdade da Distribuição } & \multicolumn{2}{|c|}{$\begin{array}{c}\text { Diferença favorável às } \\
\text { exportadoras EUA }\end{array}$} \\
\hline & Exportadoras EUA & Exportadoras & Estatística & $p$-value & Estatística & $p$-value \\
\hline $\begin{array}{l}\text { Firmas exportadoras } \\
\text { EUA vs. Firmas } \\
\text { exportadoras }\end{array}$ & 2438 & 23058 & 0.0738 & 0.0010 & 0.0075 & 0.9280 \\
\hline $\begin{array}{l}\text { Firmas exportadoras } \\
\text { EUA de pequeno porte } \\
\text { vs. Firmas de pequeno } \\
\text { porte exportadoras }\end{array}$ & 1343 & 6634 & 0.1246 & 0.0370 & 0.0167 & 0.9310 \\
\hline $\begin{array}{l}\text { Firmas exportadoras } \\
\text { EUA de grande porte vs. } \\
\text { Firmas de grande porte } \\
\text { exportadoras }\end{array}$ & 1127 & 5064 & 0.1165 & 0.0360 & 0.0279 & 0.7940 \\
\hline
\end{tabular}

Fonte: Cálculo dos autores. 
TABELA 9 - TESTE ESTATÍSTICO COMPARATIVO ENTRE A TAXA DE CRESCIMENTO DE PTF PARA AS FIRMAS EXPORTADORAS PARA OS ESTADOS UNIDOS E PARA AS FIRMAS EXPORTADORAS PARA OUTROS MERCADOS INTERNACIONAIS - CONJUNTO DAS FIRMAS, FIRMAS DE PEQUENO PORTE E FIRMAS DE GRANDE PORTE

\begin{tabular}{|c|c|c|c|c|c|c|}
\hline & \multicolumn{2}{|c|}{ Número de Observações } & \multicolumn{2}{|c|}{ Igualdade da Distribuição } & \multicolumn{2}{|c|}{$\begin{array}{c}\text { Diferença favorável às } \\
\text { exportadoras EUA }\end{array}$} \\
\hline & Exportadoras EUA & Exportadoras & Estatística & $p$-value & Estatística & $p$-value \\
\hline $\begin{array}{l}\text { Firmas exportadoras EUA } \\
\text { vs. Firmas exportadoras }\end{array}$ & 2438 & 23058 & 0.0081 & 0.467 & -0.0245 & 0.001 \\
\hline $\begin{array}{l}\text { Firmas exportadoras EUA } \\
\text { de pequeno porte vs. } \\
\text { Firmas de pequeno porte } \\
\text { exportadoras }\end{array}$ & 943 & 6634 & 0.0403 & 0.028 & -0.0420 & 0.020 \\
\hline $\begin{array}{l}\text { Firmas exportadoras } \\
\text { EUA de grande porte vs. } \\
\text { Firmas de grande porte } \\
\text { exportadoras }\end{array}$ & 1027 & 5064 & 0.0955 & 0.000 & -0.0034 & 0.965 \\
\hline
\end{tabular}

Fonte: Cálculo dos autores.

\section{CONCLUSÕES}

O processo de abertura comercial tem trazido mudanças importantes para a economia brasileira. A abertura tem obrigado as empresas a melhorar os níveis de produtividade a fim de se inserir de forma competitiva no mercado internacional. Por sua vez, a maior inserção das firmas brasileiras no mercado exportador tem levado o Brasil a mostrar elevadas taxas de crescimento das exportações nos últimos anos. Uma análise dos fatores ao nível das firmas é necessária para um melhor entendimento das exportações brasileiras no período recente.

Este trabalho analisou as diferenças de produtividade entre firmas exportadoras e firmas não exportadoras no Brasil, apresentando novas evidências. O trabalho foi realizado usando microdados da PIA, da SECEX e da RAIS, disponíveis para o período 1997-2003. No que tange aos aspectos teóricos, o trabalho se apoiou na teoria microeconômica do comércio. A análise empírica consistiu na realização do teste não paramétrico Kolmogorov-Smirnov, comparando distribuições de produtividade de diversos grupos de firmas (as sempre exportadoras, as entrantes no comércio internacional, as que saíram do mercado internacional no período em análise e as nunca exportadoras). 
Os resultados encontrados mostram claramente maiores níveis de produtividade para as firmas exportadoras do que para as firmas não exportadoras no Brasil. Esta evidência empírica encontrada parece ser mais contundente para o grupo de firmas de pequeno porte; neste grupo, as empresas exportadoras têm claramente maior nível de produtividade do que as não exportadoras.

A fim de explicar essas diferenças de produtividade, foram consideradas duas hipóteses comumente usadas na literatura: processos de seleção e processos de aprendizado no comércio internacional. As evidências empíricas encontradas parecem dar suporte à primeira hipótese, i.e., o maior nível de produtividade das firmas exportadoras parece ser fruto de processos de seleção das firmas não apenas na entrada, mas também na saída do mercado de exportação. Esta evidência parece ser mais robusta para o grupo das firmas de pequeno porte.

Quanto à segunda hipótese, as evidências encontradas não parecem confirmar a existência de processos de aprendizado no mercado exportador brasileiro. Durante o período considerado, a taxa de crescimento de produtividade de firmas exportadoras e firmas não exportadoras não parece ser estatisticamente diferente.

O destino do mercado pode ser uma variável importante para explicar a diferença de produtividade das firmas que comercializam seus produtos no exterior. $\mathrm{O}$ exercício empírico do trabalho mostrou algumas evidências favoráveis à seleção de firmas exportadoras para mercados maiores e mais competitivos. Por sua vez, não aparenta haver um maior aprendizado de firmas exportadoras para tais maiores mercados.

A análise dos resultados acima apresentada, entretanto, deve ser vista com o devido cuidado. Uma análise mais abrangente mostrará que existem outros fatores que também podem ter influenciado o crescimento da produtividade ao longo do tempo entre firmas exportadoras e firmas não exportadoras. Assim, por exemplo, o processo de abertura comercial aparentemente promoveu melhorias na produtividade. ${ }^{8} \mathrm{O}$ processo de concorrência das importações nos mercados brasileiros tornou-se uma potencial ameaça para os produtores domésticos, obrigando as firmas a se tornarem mais eficientes. Da mesma forma a liberalização comercial tornou mais acessível a importação de tecnologia, equipamentos de informática, insumos intermediários e bens de capital, entre outros, que tiveram efeitos positivos sobre o crescimento da produtividade. Por outro lado, o crescimento da PTF das firmas exportadoras pode também estar associado ao crescimento das exportações durante o período, aspecto este não analisado no presente estudo.

Extensões do presente trabalho deverão incorporar estimativas da produtividade total dos fatores (PTF) via o método apresentado em Olley e Pakes (1996) e em

8 Ver a respeito Hidalgo (2002) e Ferreira e Guillén (2004). 
Levinsohn e Petrin (2003), com o intuito de isolar potenciais efeitos de características não observáveis sobre os coeficientes estimados da função de produção. Sugere-se também estudar o potencial problema das variáveis omitidas e o viés de seleção a fim de identificar de maneira precisa o efeito do comércio sobre a produtividade.

\section{REFERENCIAS}

AW, B. Y.; HWANG, A . Productivity and the export market: A firm-level analysis. Journal of Development Economics, v. 47, p. 313-332, 1995.

AW, B. Y.; CHUNG, S.; ROBERTS, M. J. Productivity and turnover in the export market: micro evidence from Taiwan and South Korea. The World Bank Economic Review, v. 14, n. 1, p. 65-90, 2000.

BERNARD, A. B. et alii. Plants and productivity in international trade. American Economic Review, v. 93, n. 4, p. 1268-1290, 2003.

; JENSEN, J. B. Why some firms export? The Review of Economics and Statistics, p. 561-569, 2004.

BONELLI, R.; FONSECA, R. Ganhos de produtividade e de eficiência: novos resultados para a economia brasileira. RJ: IPEA, 1998.(Texto para Discussão, n. 557).

CAVES, D. W.; CHRISTENSEN, L. R.; DIEWERT, E. Multilateral comparisons of output , input, and productivity using superlative index numbers. The Economic Journal, v. 92, p. 73-86, 1982.

CONOVER, W. J. Practical nonparametric statistics. 3ed. New York: John Wiley and Sons, Inc., 1999.

DELGADO, M. A.; FARIÑAS, J. C.; RUANO, S. Firm productivity and export markets: a non-parametric approach. Journal of International Economics, v. 57, n. 2 , p. 397- $422,2002$.

DOSI, G. Sources, procedures and microeconomics effects of innovation. Journal of Economic Literature, 26, p. 1120-1171, Sept. 1988.

EATON, J.; KORTUM, S.; KRAMARZ, F. Dissecting trade: firms, industries, and export destinations. American Economic Review, v. 94, n. 2, p. 150-154, 2004.

FERREIRA, P. C.; GUILLÉN, O. T. Estrutura competitiva, produtividade industrial e liberalização comercial no Brasil. Revista Brasileira de Economia, v. 58, n. 4, p. 507-532, 2004.

.; Rossi, J. L. New evidence from Brazil on trade liberalization and productivity growth. International Economic Review, v. 44, n. 4, p. 1383-1405, 2003.

GOMES, V.; ELLERY, R. G., Jr. Perfil das exportações, produtividade e tamanho das firmas no Brasil. Revista Brasileira de Economia, v. 61, n. 1, p. 33- 48, 2007.

HAY, D. A. The post-1990 Brazilian trade liberalisation and the performance of large manufacturing firms: productivity, market share and profits. Economic Journal, v. 111, p. 620-641, 2001. 
HIDALGO, A. B. O processo de abertura comercial brasileira e o crescimento da produtividade. Revista Economia Aplicada, v. 6, n. 1, p. 79-95, 2002.

LEVINSOHN, J.; PETRIN, A. K. Estimating production functions using inputs to control for unobservables. Review of Economic Studies, v. 70, n. 2, p. 317-342, 2003.

MELITZ, M. J. The impact of trade on intra-industry real-locations and aggregate industry productivity. Econometrica, v. 71, n. 6, p. 1695-1725, 2003.

OLLEY, S.; PAKES, A. The dynamics of productivity In the telecommunications equipment industry. Econometrica, v. 64, p. 1263-1297, 1996.

ROBERTS, M. J.; TYBOUT, J. R. The decision to export in Colombia: an empirical model of entry with sunk costs. American Economic Review, 87, p. 545-564, 1997.

ROSSI JUNIOR, J. L.; FERREIRA, P. C.. Evolução da produtividade industrial brasileira e abertura comercial. Pesquisa e Planejamento Econômico, v. 29, n. 1, p. 1-36, 1999.

SABOIA, J. Produtividade na indústria brasileira no passado recente: um estudo dos diferenciais intersetoriais. Revista Economia Aplicada, v. 8, n. 1, p. 165-199, 2004.

SOLOW, R. Technical change and the aggregate production function. Review of Economics and Statistics, v. 39, p. 312- 320, 1957.

TYBOUT, J. R. Plant and firms level evidence on new trade theories. In: CHOI, E. K.; Harrigan, J. (Eds.). Handbook of international trade. Blackwell Publishing, 2003. p. 388-415. 


\section{ANEXO}

TABELA A.I - TESTE ESTATÍSTICO DAS DIFERENÇAS DE PL ENTRE FIRMAS EXPORTADORAS E NÃO EXPORTADORAS - CONJUNTO DE TODAS AS FIRMAS

\begin{tabular}{|c|c|c|c|c|c|c|}
\hline \multirow[t]{3}{*}{ Ano } & \multicolumn{6}{|c|}{ Firmas sempre exportadoras vs. Firmas nunca exportadoras } \\
\hline & \multicolumn{2}{|c|}{$\begin{array}{l}\text { Número de } \\
\text { observações }\end{array}$} & \multicolumn{2}{|c|}{$\begin{array}{l}\text { Igualdade da } \\
\text { distribuição }\end{array}$} & \multicolumn{2}{|c|}{$\begin{array}{l}\text { Diferença favorável às } \\
\text { exportadoras }\end{array}$} \\
\hline & Exportadoras & Não exportadoras & Estatística & $p$-value & Estatística & $p$-value \\
\hline 1997 & 3167 & 11444 & 0,4716 & 0,000 & 0,0004 & 0,999 \\
\hline 1998 & 3307 & 12286 & 0,4850 & 0,000 & 0,0000 & 1,000 \\
\hline 1999 & 3330 & 12540 & 0,5463 & 0,000 & 0,0002 & 1,000 \\
\hline 2000 & 3301 & 12884 & 0,5512 & 0,000 & 0,0001 & 1,000 \\
\hline 2001 & 3306 & 13920 & 0,5781 & 0,000 & 0,0000 & 1,000 \\
\hline 2002 & 3345 & 15092 & 0,5823 & 0,000 & 0,0000 & 1,000 \\
\hline 2003 & 3302 & 16165 & 0,5687 & 0,000 & 0,0000 & 1,000 \\
\hline Todos os anos & 23058 & 94331 & 0,5325 & 0,000 & 0,0000 & 1,000 \\
\hline
\end{tabular}

Fonte: Cálculo dos autores.

TABELA A.2 - TESTE ESTATÍSTICO DAS DIFERENÇAS DE PL ENTRE FIRMAS EXPORTADORAS E NÃO EXPORTADORAS- FIRMAS DE GRANDE PORTE

\begin{tabular}{|c|c|c|c|c|c|c|}
\hline \multirow[t]{3}{*}{ Ano } & \multicolumn{6}{|c|}{ Firmas de grande porte sempre exportadoras vs. Firmas de grande porte nunca exportadoras } \\
\hline & \multicolumn{2}{|c|}{$\begin{array}{l}\text { Número de } \\
\text { Observações }\end{array}$} & \multicolumn{2}{|c|}{$\begin{array}{l}\text { Igualdade da } \\
\text { Distribuição }\end{array}$} & \multicolumn{2}{|c|}{$\begin{array}{l}\text { Diferença favorável às } \\
\text { exportadoras }\end{array}$} \\
\hline & Exportadoras & Não exportadora & Estatística & $p$-value & Estatística & p-value \\
\hline 1997 & 723 & 177 & 0,2744 & 0,000 & 0,0000 & 1,0000 \\
\hline 1998 & 686 & 141 & 0,2396 & 0,000 & 0,0029 & 0,9980 \\
\hline 1999 & 679 & 131 & 0,3219 & 0,000 & 0,0000 & 1,0000 \\
\hline 2000 & 712 & 120 & 0,3604 & 0,000 & 0,0000 & 1,0000 \\
\hline 2001 & 740 & 127 & 0,3517 & 0,000 & 0,0065 & 0,9910 \\
\hline 2002 & 757 & 141 & 0,3255 & 0,000 & 0,0058 & 0,9920 \\
\hline 2003 & 767 & 167 & 0,3025 & 0,000 & 0,0060 & 0,9900 \\
\hline Todos os anos & 5064 & 1004 & 0,2987 & 0,000 & 0,0016 & 0,9960 \\
\hline
\end{tabular}

Fonte: Cálculo dos autores. 
TABELA A.3 - TESTE ESTATÍSTICO DAS DIFERENÇAS DE PL ENTRE FIRMAS EXPORTADORAS E NÃO EXPORTADORAS - FIRMAS DE PEQUENO PORTE

\begin{tabular}{|c|c|c|c|c|c|c|}
\hline \multirow[t]{3}{*}{ Ano } & \multicolumn{6}{|c|}{ Firmas de pequeno porte sempre exportadoras vs. Firmas de pequeno porte nunca exportadoras } \\
\hline & \multicolumn{2}{|c|}{$\begin{array}{l}\text { Número de } \\
\text { observações }\end{array}$} & \multicolumn{2}{|c|}{$\begin{array}{l}\text { Igualdade da } \\
\text { distribuição }\end{array}$} & \multicolumn{2}{|c|}{$\begin{array}{c}\text { Diferença favorável às } \\
\text { exportadoras }\end{array}$} \\
\hline & Exportadoras & Não exportadoras & Estatística & $p$-value & Estatística & $p$-value \\
\hline 1997 & 915 & 7671 & 0,4542 & 0,000 & 0,0004 & 1,000 \\
\hline 1998 & 995 & 7900 & 0,4769 & 0,000 & 0,0001 & 1,000 \\
\hline 1999 & 980 & 8240 & 0,5508 & 0,000 & 0,0002 & 1,000 \\
\hline 2000 & 929 & 9013 & 0,5419 & 0,000 & 0,0000 & 1,000 \\
\hline 2001 & 930 & 9786 & 0,5534 & 0,000 & 0,0003 & 1,000 \\
\hline 2002 & 960 & 10522 & 0,5656 & 0,000 & 0,0000 & 1,000 \\
\hline 2003 & 925 & 11057 & 0,5694 & 0,000 & 0,0002 & 1,000 \\
\hline Todos os anos & 6634 & 64189 & 0,5157 & 0,000 & 0,0000 & 1,000 \\
\hline
\end{tabular}

Fonte: Cálculo dos autores.

TABELA A.4 - TESTE ESTATÍSTICO COMPARATIVO ENTRE A DISTRIBUIÇÃO DE PL ENTRE FIRMAS ENTRANTES E NÃO EXPORTADORAS - PARA O CONJUNTO DAS FIRMAS, FIRMAS DE PEQUENO PORTE E FIRMAS DE GRANDE PORTE

\begin{tabular}{|c|c|c|c|c|c|c|}
\hline \multirow[t]{2}{*}{ Ano $=1997$} & \multicolumn{2}{|c|}{$\begin{array}{l}\text { Número de } \\
\text { observações }\end{array}$} & \multicolumn{2}{|c|}{$\begin{array}{l}\text { Igualdade da } \\
\text { distribuição }\end{array}$} & \multicolumn{2}{|c|}{$\begin{array}{c}\text { Diferença favorável às } \\
\text { exportadoras }\end{array}$} \\
\hline & Entrantes & Não exportadoras & Estatística & $p$-value & Estatística & $p$-value \\
\hline $\begin{array}{l}\text { Firmas entrantes vs. Firmas nunca } \\
\text { exportadoras }\end{array}$ & 258 & 11444 & 0,2639 & 0,0000 & 0,0003 & 1,0000 \\
\hline $\begin{array}{l}\text { Firmas entrantes de pequeno porte } \\
\text { vs. Firmas de pequeno porte nunca } \\
\text { exportadoras }\end{array}$ & 145 & 7671 & 0,3729 & 0,1440 & 0,1486 & 0,6580 \\
\hline $\begin{array}{l}\text { Firmas entrantes de grande porte } \\
\text { vs. Firmas de grande porte nunca } \\
\text { exportadoras }\end{array}$ & 10 & 177 & 0,2972 & 0,0000 & 0,0056 & 0,9910 \\
\hline
\end{tabular}

Fonte: Cálculo dos autores. 
TABELA A.5 - TESTE ESTATÍSTICO COMPARATIVO ENTRE A DISTRIBUIÇÃO DE PL EX-ANTE DAS FIRMAS QUE DEIXAM O MERCADO EXPORTADOR E DAS FIRMAS QUE NUNCA EXPORTARAM

\begin{tabular}{|c|c|c|c|c|c|c|}
\hline \multirow[t]{3}{*}{ Todos os anos } & \multicolumn{6}{|c|}{ Firmas "exiting" vs. Firmas nunca exportadoras } \\
\hline & \multicolumn{2}{|r|}{$\begin{array}{l}\text { Número de } \\
\text { observações }\end{array}$} & \multicolumn{2}{|c|}{$\begin{array}{l}\text { Igualdade da } \\
\text { distribuição }\end{array}$} & \multicolumn{2}{|c|}{$\begin{array}{c}\text { Diferença favorável às } \\
\text { exportadoras }\end{array}$} \\
\hline & Exiting & Nunca exportadoras & Estatística & $p$-value & Estatística & $p$-value \\
\hline $\begin{array}{l}\text { Firmas "exiting" vs. Firmas nunca } \\
\text { exportadoras }\end{array}$ & 1532 & 94331 & 0,2786 & 0,0000 & 0,0000 & 1,0000 \\
\hline $\begin{array}{l}\text { Firmas de grande porte "exiting" } \\
\text { vs. Firmas de grande porte nunca } \\
\text { exportadoras }\end{array}$ & 170 & 1004 & 0,0822 & 0,2130 & 0,0362 & 0,6480 \\
\hline $\begin{array}{l}\text { Firmas de pequeno porte "exiting" } \\
\text { vs. Firmas de pequeno porte nunca } \\
\text { exportadoras }\end{array}$ & 620 & 64189 & 0,3232 & 0,0000 & 0,0003 & 1,0000 \\
\hline
\end{tabular}

Fonte: Cálculo dos autores.

\section{TABELA A.6 - TESTE ESTATÍSTICO DA TAXA DE CRESCIMENTO DE PL PARA AS FIRMAS EXPORTADORAS E PARA AS FIRMAS NÃO EXPORTADORAS}

\begin{tabular}{|c|c|c|c|c|c|c|}
\hline \multirow[t]{2}{*}{ Todos os anos } & \multicolumn{2}{|c|}{$\begin{array}{l}\text { Número de } \\
\text { observações }\end{array}$} & \multicolumn{2}{|c|}{$\begin{array}{l}\text { Igualdade da } \\
\text { distribuição }\end{array}$} & \multicolumn{2}{|c|}{$\begin{array}{c}\text { Diferença favorável às } \\
\text { exportadoras }\end{array}$} \\
\hline & Exportadoras & Não exportadoras & Estatística & $p$-value & Estatística & $p$-value \\
\hline $\begin{array}{l}\text { Firmas sempre exportadoras vs. } \\
\text { Firmas nunca exportadoras }\end{array}$ & 23058 & 94331 & 0,1617 & 0,0000 & $-0,0252$ & 0,1200 \\
\hline $\begin{array}{l}\text { Firmas sempre exportadoras } \\
\text { de grande porte vs. Firmas de } \\
\text { grande porte nunca exportadoras }\end{array}$ & 5064 & 1004 & 0,1894 & 0,0020 & $-0,0162$ & 0,9490 \\
\hline $\begin{array}{l}\text { Firmas sempre exportadoras } \\
\text { de pequeno porte vs. Firmas } \\
\text { de pequeno porte nunca } \\
\text { exportadoras }\end{array}$ & 6634 & 64189 & 0,1627 & 0,0000 & $-0,0116$ & 0,8750 \\
\hline
\end{tabular}

Fonte: Cálculo dos autores. 
TABELA A.7 - TESTE ESTATÍSTICO COMPARATIVO ENTRE A DISTRIBUIÇÃO DE PL DAS FIRMAS EXPORTADORAS PARA OS EUA E EXPORTADORAS PARA OUTROS MERCADOS INTERNACIONAIS - CONJUNTO DAS FIRMAS, FIRMAS DE PEQUENO PORTE E FIRMAS DE GRANDE PORTE

\begin{tabular}{|c|c|c|c|c|c|c|}
\hline & \multicolumn{2}{|c|}{$\begin{array}{l}\text { Número de } \\
\text { Observações }\end{array}$} & \multicolumn{2}{|c|}{$\begin{array}{l}\text { Igualdade da } \\
\text { Distribuição }\end{array}$} & \multicolumn{2}{|c|}{$\begin{array}{l}\text { Diferença favorável às } \\
\text { exportadoras EUA }\end{array}$} \\
\hline & $\begin{array}{l}\text { Exportadoras } \\
\text { EUA }\end{array}$ & Exportadoras & Estatística & $p$-value & Estatística & $p$-value \\
\hline $\begin{array}{l}\text { Firmas exportadoras EUA vs. Firmas } \\
\text { exportadoras }\end{array}$ & 2438 & 23058 & 0.1262 & 0.0000 & 0.0017 & 0.9960 \\
\hline $\begin{array}{l}\text { Firmas exportadoras EUA de pequeno } \\
\text { porte vs. Firmas de pequeno porte } \\
\text { exportadoras }\end{array}$ & 943 & 6634 & 0.1108 & 0.0860 & 0.0105 & 0.9720 \\
\hline $\begin{array}{l}\text { Firmas exportadoras EUA de grande } \\
\text { porte vs. Firmas de grande porte } \\
\text { exportadoras }\end{array}$ & 1027 & 5064 & 0.1194 & 0.0290 & 0.0128 & 0.9530 \\
\hline
\end{tabular}

Fonte: Cálculo dos autores.

TABELA A.8 - TESTE ESTATÍSTICO COMPARATIVO ENTRE A TAXA DE CRESCIMENTO DE PL PARA AS FIRMAS EXPORTADORAS PARA OS ESTADOS UNIDOS E PARA AS FIRMAS EXPORTADOR AS PARA OUTROS MERCADOS INTERNACIONAIS - CONJUNTO DAS FIRMAS, FIRMAS DE PEQUENO PORTE E FIRMAS DE GRANDE PORTE

\begin{tabular}{|c|c|c|c|c|c|c|}
\hline & \multicolumn{2}{|c|}{$\begin{array}{l}\text { Número de } \\
\text { Observações }\end{array}$} & \multicolumn{2}{|c|}{$\begin{array}{l}\text { Igualdade da } \\
\text { Distribuição }\end{array}$} & \multicolumn{2}{|c|}{$\begin{array}{l}\text { Diferença favorável às } \\
\text { exportadoras EUA }\end{array}$} \\
\hline & $\begin{array}{c}\text { Exportadoras } \\
\text { EUA }\end{array}$ & Exportadoras & Estatística & $p$-value & Estatística & $p$-value \\
\hline $\begin{array}{l}\text { Firmas exportadoras EUA vs. Firmas } \\
\text { exportadoras }\end{array}$ & 2438 & 23058 & 0.0979 & 0.000 & -0.0001 & 1.0000 \\
\hline $\begin{array}{l}\text { Firmas exportadoras EUA de pequeno } \\
\text { porte vs. Firmas de pequeno porte } \\
\text { exportadoras }\end{array}$ & 943 & 6634 & 0.1193 & 0.000 & -0.0023 & 0.9880 \\
\hline $\begin{array}{l}\text { Firmas exportadoras EUA de grande } \\
\text { porte vs. Firmas de grande porte } \\
\text { exportadoras }\end{array}$ & 1027 & 5064 & 0.0679 & 0.000 & -0.0048 & 0.931 \\
\hline
\end{tabular}

Fonte: Cálculo dos autores. 